\title{
La defensa de la Iglesia ante la legislación liberal en el periodo 1855-1861
}

\author{
Javier Rodríguez Piña \\ DEPARTAMENTO DE SOCIOLOGIA-UAM-A
}

\begin{abstract}
En este trabajo se hace un recuento del material publicado principalmente por la alta jerarquía católica en el que se expresa la posición de la Iglesia ante las distintas leyes liberales expedidas entre 1855 y 1861.
\end{abstract}

El torrente de lágrimas que han derramado los buenos mexicanos por las atrocidades cometidas con el clero, bien podía formar un caudaloso río: mas siempre insuficiente para borrar tantos crímenes perpetrados bajo la égida de lo que se llama ley y libertad. ${ }^{1}$

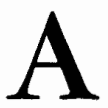

1 triunfo del movimiento iniciado con el Plan de Ayutla, los liberales - moderados y purostuvieron la oportunidad de empezar a poner en marcha sus proyectos de organización del país y de reordenamiento de sus instituciones. Ello signi-

1 Labastida, Protesta, 1858, p. 47. ficó un ataque directo a aquello que consideraban expresión del viejo "orden colonial", especialmente instituciones que, como la Iglesia, reunían todavía dosis de poder, riqueza y privilegios lo suficientemente fuertes como para constituir frenos para la reforma del país.

Si bien en el proyecto de 1855 los liberales no hacian sino continuar con la tradición confiscatoria hacia los bienes de la Iglesia, cuyo origen se remontaba al periodo inmediatamente posterior a la independencia ${ }^{2}$-y que fue

\footnotetext{
${ }^{2}$ El gobierno de Iturbide recibió, junto con enormes deudas y como herencia del gobiemo
} 
continuada en 1833,1843 y $1846-3$ en realidad, en esa ocasión, a diferencia de las experiencias anteriores y con excepción de lo ocurrido en 1833 , la expropiación contra la Iglesia fue acompañada de un amplio programa de reformas que fueron más allá de la simple necesidad de hacerse de recursos económicos.

En principio, con la reforma iniciada en 1855, los liberales se propusieron terminar con los privilegios corporativos que la Iglesia había tenido desde la época colonial, bajo la idea de que el poder económico y político que ésta había acumulado eran el principal obstáculo para la conformación

virreinal, bienes eclesiásticos provenientes tanto de la inquisición como del Fondo Piadoso de las Californias y de las "temporalidades", o sea, los bienes de las órdenes suprimidas en el siglo XVIII. Agustín de Iturbide pretendió inútilmente primero hipotecarlos y después venderlos para hacerse de fondos para su gobierno imperial. Véase: Bazant, Bienes; Knowlton, Bienes, 1985.

${ }^{3}$ En 1833, como producto de la vicepresidencia de Valentín Gómez Farías, se puso en marcha todo un programa de reformas liberales que afectaban directamente a la Iglesia. Desde el punto de vista económico, se dispuso -entre otras medidas destinadas a controlar Ja riqueza de esta corporación por parte del Estado- la prohibición de que las órdenes religiosas y cofradias traspasaran sus bienes raíces en el Distrito Federal sin aprobación del gobierno, y se anularon todas estas transferencias a partir de 1821. Asimismo, se puso fin a la coacción civil para recabar diezmos e imponer el cumplimiento de los votos monásticos. Diez años más tarde, en 1843, Santa Anna prohibió la enajenación de propiedades de todos los establecimientos piadosos sin una autorización especial del gobierno $y$, en 1846 , en medio de la guerra contra Estados Unidos, se aprobó la ley que autorizó al gobierno a conseguir 15000000 de pesos hipotecando o rematando propiedades de la Iglesia. de la nación mexicana. En tal sentido, a partir de noviembre del mismo año, se comenzaron a expedir diversas leyes destinadas a disminuir la capacidad de acción de la Iglesia en el ámbito civil, y otras reservadas a expropiar sus bienes y posesiones y a controlar sus ingresos.

De esa manera, entre 1855 y 1861 se aplicaron diversas leyes liberales que afectaron directamente a la Iglesia católica, frente a las cuales, la jerarquía eclesiástica fue reaccionando de distintos modos - a través de exposiciones, representaciones, reclamaciones y protestas- ante los sucesivos gobiernos de Juan Álvarez, Ignacio Comonfort y Benito Juárez e, incluso, por medio de la defensa violenta de sus principios. En este sentido, la publicación de folletos por parte de la Iglesia, donde se expresaba la posición de la jerarquía en torno a lo que se vivía como un ataque directo a la religión, se convirtió en un medio factible para la difusión de sus argumentos defensivos frente a las leyes y los actos del gobierno.

Bajo esta perspectiva, la intención de este trabajo es hacerun recuento global del tipo de material publicado por la jerarquía religiosa, y otros sectores católicos, en el que se expresa la posición de la Iglesia frente a las distintas leyes liberales que se fueron expidiendo entre 1855 y 1861.

LOS DIFERENTES MOMENTOS

DE LA DIFENSA RELIGIOSA

Una primera consideración de índole cuantitativa tiene que hacerse en cuan- 


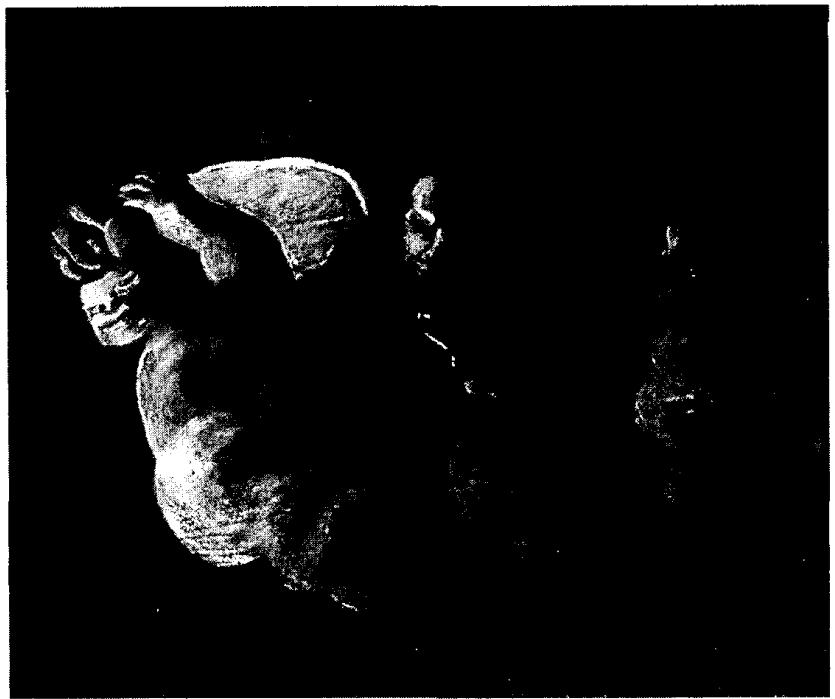

to al material relativo al tema, publicado en folleto y cuya referencia está disponible en la base de datos recopilada por el Instituto Mora: se trata de un conjunto de folletos cuyo volumen no supera los 200 títulos, lo cual representa aproximadamente sólo el 14.8\% del total de la folletería publicada en el mismo periodo. En este recuento no se incluyeron ni los sermones, ni las pastorales, ni otros materiales de tipo religioso, a menos que se hiciera referencia explícita al debate contra la legislación liberal.

Una segunda consideración se refiere al tipo de material localizado. Se trata esencialmente de folletos publicados por parte de la alta jerarquía católica y en muy poca proporción por sectores de menor rango. De la misma manera, casi no existe material proveniente de los sectores "radicales" del clero, es decir, de aquellos que participaron directamente en los levantamientos armados contra el gohierno antes de diciembre de 1857 , y de quienes intervinieron posteriormente en la guerra de los Tres Años. En todo caso, estamos ante un material que se constituye como la voz "oficial" del clero en este lapso, durante el cual, va "endureciendo" sin embargo, el discurso conforme se van dando los acontecimientos.

En la panorámica general del periodo, podemos distinguir cinco momentos, en torno a los cuales, se aglutina la mayor parte de la folletería publicada acerca del tema. En todos los casos, se trata de momentos vinculados a la 
expedición o discusión de leyes y a la reacción específica que se desató como consecuencia de ello. Estos cinco momentos son los siguientes:

1. El primero, que corresponde además al inicio del conflicto, es el que está asociado a la expedición de la ley conocida como Ley Juárez del 22 de noviembre de 1855 . Se trata de la primera modificación legislativa hecha por los liberales en el poder, que estableció la prohibición de que los tribunales eclesiásticos y militares conocieran de asuntos civiles, y dispuso que el fuero eclesiástico fuera renunciable en delitos del orden común.

La lectura inmediata que la Iglesia hizo de esta ley, en el sentido de que era un ataque directo al fuero religioso, la llevó a manifestarse inmediatamente en contra y a rechazar la facultad que el gobierno tenía de intervenir y limitar los derechos de la institución religiosa. En ese sentido, la posición oficial de la Iglesia fue expresada por el propio arzobispo de México, Lázaro de la Garza y Ballesteros, ante Benito Juárez, ministro de Justicia y Negocios Eclesiásticos de Juan Álvarez:

hago [...] la más solemne protesta que hacerse deba y sea necesaria contra el art. 42 de la ley en la parte que dispone la cesación del fuero en lo civil, y en contra de cualquier disposición que lo quite en lo que anuncia con respecto a lo criminal. De la misma manera, [...] declaro que el art. 44 es contrario a lo dispuesto por la Iglesia: que la renuncia que cualquier individuo del clero haga del fuero, ya sea en lo civil ya en lo criminal, es nula y de ningún momento aun cuando lo jure; y que ya sea la renuncia de grado o por la fuerza, sobre ser de ningún valor quedará por lo mismo sujeto el que la haga a las penas que Ia Iglesia impone a los contraventores; protestando como protesta contra dicho artículo. ${ }^{4}$

Aunque el desafuero que inició el gobierno de Álvarez provocó movimientos de rebeldía encabezados por miembros del clero (entre los cuales destaca el dirigido en Puebla por el cura Francisco Ortega García a través del Plan de Zacapoaxtla), en la folletería conocida de este periodo sólo está presente, al principio, la posición oficial de la jerarquía eclesiástica, la cual intentó, esencialmente a través de sus representantes regionales de alto nivel, expresar desacuerdo ante las modificaciones legales.

Posteriormente, como consecuencia de la expedición, el 31 de marzo de 1856, del decreto con el cual, el presidente Ignacio Comonfort intentó escarmentar a los sublevados expropiando los bienes de la diócesis poblana para indemnizar al gobierno de los gastos provocados por el levantamiento, la folletería está orientada a reclamarle al gobierno, de manera cuidadosa pero firme, su derecho a confiscar los bienes de la Iglesia por contravenir ello sus leyes ancestrales. Así lo señala el obispo de Puebla:

El decreto que interviene los bienes eclesiásticos de mi diócesis, está en oposición abierta con las leyes de la Iglesia: cuanto se opone a éstas se opone a la ley de Dios, y repito que me hallo en la alternativa de faltar a Dios o rehusar mi

${ }^{4}$ Garza, Contestaciones, 1855, p. 7. 
consentimiento a la disposición del gobierno. [...] En medidas extremas y en la alternativa de obedecer a Dios o al César, no hay medio, y la prudencia cristiana aconseja lo primero, sea cual fueren las consecuencias que puedan resultar, y que por mi parte he procurado evitar, haciendo los mayores esfuerzos. ${ }^{5}$

2. Un segundo momento del conflicto entre la Iglesia y el Estado, que se relaciona además con la publicación de folletos vinculados a un tema específico, corresponde a la etapa que se inició con la expedición, el 25 de junio de 1856 , de la Ley de Desamortización de los Bienes de las Corporaciones Civiles y Religiosas, o Ley Lerdo, con la cual literalmente se confiscaban las propiedades de la Iglesia en beneficio de los inquilinos y arrendatarios.

A partir de ese momento, en medio del aumento del conflicto y la violencia de ambos lados, se dio un incremento en la publicación de folletos dedicados a defender la posición de la Iglesia frente a esta ley, junto con una relativa radicalización del discurso religioso, como se observa en el siguiente texto del obispo de Guadalajara:

Sé que debo respetar a las supremas autoridades civiles y obsequiar sus disposiciones; pero sé también que este deber tiene sus límites que no me es lícito traspasar; que cuando lo que se me

${ }^{5}$ Labastida, Representación, 1856, pp. $10 \mathrm{y}$ 14. Es importante señalar que, en medio de la rebelión poblana, la jerarquía católica, por lo menos en los folletos publicados, tuvo mucho cuidado en deslindarse de la violencia. exige importa un desconocimiento de los sagrados derechos de la Iglesia, sería un pecado obedecer, y que debo repetir lo que San Pedro y los demás apóstoles decian: es menester obedecera Dios antes que a los hombres (Actos 6:29). El derecho que tiene la Iglesia para adquirir bienes aun inmuebles, es mil veces más respetable que el de las corporaciones civiles, que deben su existencia a la ley, y que no pueden tener otros que los que le da la misma ley, revocables al arbitrio de los legisladores; no así la Iglesia, ésta fue establecida por Jesucristo, sus derechos se los concedió su mismo divino fundador que los recibió de su Padre Celestial toda potestad en el cielo y en la tierra $[. . .]^{6}$

3. El tercer momento está claramente vinculado al debate realizado en el Congreso Constituyente, alrededor de septiembre de 1856 , en torno a la cuestión de la tolerancia religiosa. Este momento es el único en que se observa un incremento sustancial en los folletos provenientes de los sectores sociales diferentes a la jerarquía eclesiástica, de la misma manera que se da un incremento en el número de folletos publicados. Se trata de una cantidad importante de "Representaciones" hechas por habitantes de poblaciones localizadas en los distintos estados del país.

Si bien el tema no era nuevo, pues desde años atrás había estado presente en el debate a través de la folletería, ${ }^{7}$ por primera vez adquirió tintes peligrosos para la Iglesia, pues, como se

${ }^{6}$ Espinosa, Comunicaciones, 1957, p. 4.

7 Véase al respecto, en este mismo número, el trabajo de Laura Suárez de la Torre. 
vería meses más tarde, la tolerancia religiosa acabó por imponerse en la Constitución de 1857. El argumento central fue siempre muy similar al siguiente:

[...] la sana moral sólo se halla en la religión católica, $[\ldots]$ porque el Oráculo Divino es infalible, y Dios dijo a su pueblo, no habitase con los de otra religión, por el peligro de pervertirse (Exodo 23.33) porque la libertad religiosa conduce al indiferentismo, al ateísmo, al abismo en que se despeñará México para borrarse así aun del catálo. go de las naciones. ${ }^{8}$

4. El siguiente momento está totalmente relacionado a la expedición de la Constitución de 1857 . El 5 de febrero de ese año, al jurarse el nuevo código, se definió, de una vez por todas, el camino que el país seguiría, por lo menos formalmente, en cuanto a la relación del Estado con la Iglesia. En franco combate contra esta última, la flamante legislación no proclamó al catolicismo como religión de Estado y, en cambio, estableció la absoluta libertad de expresión y de prensa; así mismo, les dio valor constitucional a las Leyes Juárez y Lerdo y confirió poderes al gobierno para intervenir en cuestiones del culto y de las ceremonias religiosas, además de que limitó los derechos políticos de los sacerdotes, entre otros temas lesivos para sus intereses.

Como era de esperarse, la respuesta del clero fue inmediata. Si a lo largo de 1856 su actitud defensiva ante la

${ }^{8}$ Irigoyen, Protesta, 1859, p. 8. legislación en proceso llevo al gobierno de Comonfort a caracterizar de sediciosa su actitud, después de la expedición de la nueva Constitución, que estableció la obligación de ser jurada por parte de los sacerdotes, el conflicto se acrecentó definitivamente, sobre todo porque se siguieron expidiendo preceptos como la ley de Abolición de las Obvenciones Parroquiales (Ley Iglesias), que si bien liberó a las clases menesterosas de esa carga, le quitó al clero una fuente de ingresos muy importante. Entre enero y diciembre de 1857 , la Iglesia y Ios sectores conservadores del país mantuvieron un clima de abierta rebelión contra el gobierno y, finalmente, en el último mes, con el Plan de Tacubaya encabezado por el general Félix Zuloaga para desconocer la Constitución, comenzó la guerra civil.

En este contexto, la posición de la Iglesia fue difundida a través de folletos, los cuales se incrementaron considerablemente a lo largo de 1857 y disminuyeron rápidamente en 1858 . La razón de este cambio pareciera cleberse al inicio de la guerra: en medio del conflicto bélico, la necesidad de difundir los argumentos de la Iglesia se volvió innecesario. De cualquier manera, a lo largo de 1857 el argumento se volvió insistente: la Constitución lesionaba directamente a la religión y, por tanto, la Iglesia se opondría por todos los medios a su cumplimiento. Tal como lo expresaba en su exilio en Roma el obispo de Puebla, Pelagio Antonio de Labastida y Dávalos:

El solo hecho de su publicación está indicando que los que mandan en esa 
república quieren obligaros a cumplir con todos sus artículos; mas como entre éstos hay algunos absolutamente contrarios a las verdades fundamentales de nuestra divina religión, nos hemos visto en el caso de reclamar por ellos al supremo gobierno, rogándole y conjurándole por lo más sagrado, que se valga de cuantos medios ordinarios o extraordinarios estén a sualcance hasta conseguir que desaparezcan del código fundamental tantos errores; y si por desgracia no lo hiciere por cualquier motivo, hemos concluido formulando las más solemnes protestas y declaraciones contra los artículos indicados, para dejar así salvos los derechos de la santa iglesia y cumplir con nuestro deber de la manera que podamos[... $]^{9}$

Más adelante, el obispo de Puebla, al resumir las lesiones que la Iglesia sufría con la legislación liberal, decía resumiendo todo el proceso:

A ésta [la espiritualidad], y no a los intereses temporales, ni a las comodidades de la vida, atendemos, hermanos e hijos nuestros muy amados, cuando os exhortamos a que veáis como impíos, ateos y consiguientemente injustos e inmorales los artículos de la Constitución contra que hemos protestado; como inicuas, injustas e inmorales las leyes de intervención, desamortización y despojo de los bienes eclesiásticos; como irreligiosas y antieclesiásticas todas las órdenes, circulares, reglamentos y medidas de cualquier clase, que tiendan a disminuir las prerrogativas y exenciones de los ministros de Dios, las facultades de los obispos, la suprema autoridad del sumo pontífice y de la Santa Sede, los derechos de la Iglesia y

\footnotetext{
${ }^{9}$ Labastida, Carta, 1857, p. 3.
}

de sus sagrados institutos, y en fin, a que tengais tal legislación como indigna de ser jurada, obedecida y respetada en cuanto toque a los intereses cle Dios y de su Iglesia, de nuestra santa religión y de su celestial doctrina. ${ }^{10}$

5. El último momento que nos ocupa está asociado a la expedición, por parte del presidente Benito Juárez, cle las Leyes de Reforma, promulgaclas en el mes de julio de 1859 en medio de la guerra civil. Se trató de una serie de preceptos -dirigidos a nacionalizar los bienes del clero, establecer la separación entre el Estado y la Iglesia y remarcar la libertad de cultos-, justificados por el gobierno liberal como respuesta a la negativa de la jerarquía eclesiástica a aceptar la Constitución de $1857 \mathrm{y}$, en cambio, haberse convertido en la principal promotora de la guerra civil.

En los meses que siguieron a la expedición de las Leyes de Reforma, se incrementó nuevamente la publicación de folletos, a través de los cuales, la Iglesia intentó desconocer la nueva legislación. Para la jerarquía eclesiástica ésta representaba el grado máximo de ignominia a que se podía llegar contra la religión católica:

[El] declarar propiedad de la nación todos los bienes del clero[...] es un ataque directo a la constitución divina de la Iglesia; esto, al comunicarse, es contra lo esencial de los derechos que Jesucristo Nuestro Señor organizara para fundar la Iglesia, y bajo el aspecto político es un ensayo de socialismo, es

${ }^{10}$ Ibid., p. 26. 


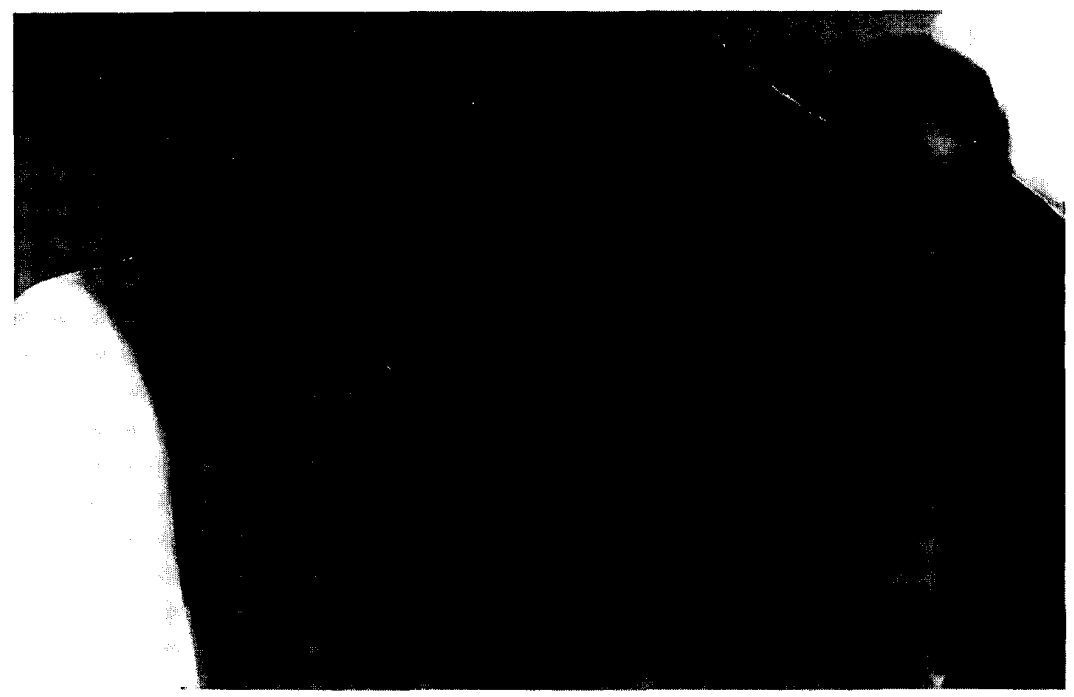

un paso del comunismo en la república mexicana, porque la propiedad de los bienes eclesiásticos es de la Iglesia, ésta es la gran propietaria de ellos, diseminados en sus fundaciones, corporaciones y singulares objetos $[\ldots]^{11}$

La mayor parte de los folletos publicados en ese momento tratarán de deslindar a la Iglesia de la acusación de promover la guerra civil. En la medida en que la nacionalización de los bienes eclesiásticos estaba justificada a partir de ese supuesto, se procuró quitarle al gobierno liberal su principal argumento.

${ }^{11}$ Irigoyen, Protesta, 1859, p. 6.
UN BALANCE GENERAL

¿Qué papel cumplió la difusión, a través de folletos, de los argumentos defensivos de la Iglesia frente a la política liberal del periodo $1855-1861$ ? Es posible pensar que fue fundamental y, sin embargo, es una mera suposición. En realidad es dificil derivar conclusiones contundentes en tal sentido, sobre todo porque las evidencias podrían marcar contradicciones.

Por un lado, aunque la publicación de folletos relativos al tema es amplia, proporcionalmente encontramos una disminución en relación con los periodos anteriores a $1855 . .^{12} \mathrm{El}$ estudioso

12 En tal sentido, véase la referencia que hace al tema Nicole Giron en este mismo número. 


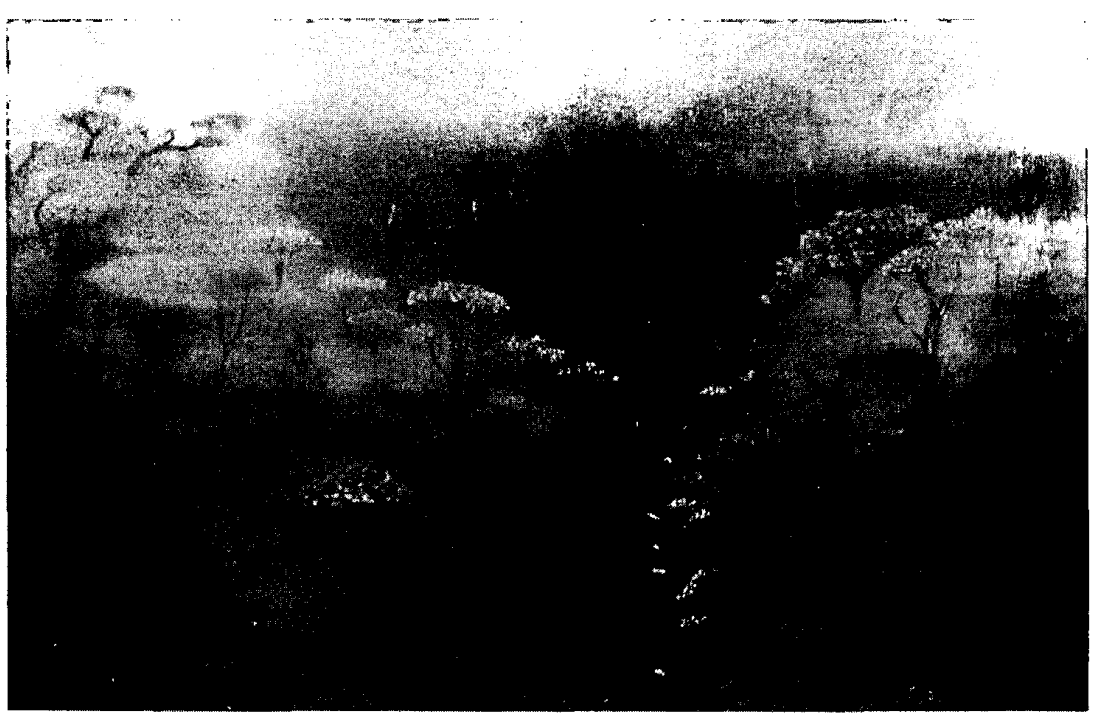

del tema esperaría encontrar una gran. profusión de textos defendiendo la posición de la Iglesia en torno al conflicto más importante que hasta entonces le había tocado vivir. Como si en medio de la confrontación con el gobierno liberal, ésta tomara una actitud prudente y prefiriera no atacar al poder.

Por otro lado, esto último resalta como rasgo de la folletería. La gran mayoría del material revisado está constituida por textos donde la confrontación radical contra el gobierno liberal no aparece. En realidad, por lo menos formalmente, resalta la actitud cautelosa antes que la violencia argumentativa. Sin embargo, conforme avanza la política liberal del gobierno, hacia 1857 , aparece el radicalismo en su argumentación.
Bajo estas condiciones, se puede hacer un balance general del material disponible en torno al tema, de acuerdo con sus características:

1. El volumen de folletos sobre el tema, en el periodo 1855-1861, es alto pero no excesivo.

2. La mayor parte del material proviene de la alta jerarquía religiosa.

3. Contrariamente, a lo que habia ocurrido hasta 1855, no se encuentran folletos publicados provenientes de lo que genéricamente se conoce como el sector conservador, como si después del fracaso de la dictadura santannista hubieran desaparecido ideológicamente.

4. La mayor proporción de los folletos fue publicada entre 1855 y 1857 ; a partir de 1858 y 1861 tiende a dismi- 
nuir su número. Después de 1861 prácticamente desaparece el tema político dentro de los folletos "religiosos". El año en que más material se publicó es 1857.

5. Como se mencionó al principio, la división de la folletería sobre el tema en cinco momentos diferentes corresponde a hechos especificos en el avance legislativo liberal, y se refiere a temas precisos en torno a los cuales se puede agrupar la gran mayoría de los folletos, a saber: desafuero de la Iglesia, desamortización de los bienes eclesiásticos, tolerancia religiosa, rechazo a la Constitución de 1857 y rechazo a las Leyes de Reforma.

6. La mayor parte del material proviene de imprentas ubicadas en la ciudad de México, Guadalajara y Puebla.

\section{BIBLIOGRAFIA}

-Bazant, Jan, Los bienes de la Iglesia en México (1856-1875). Aspectos económicos y sociales de la revolución liberal, $\mathrm{El}$ Colegio de México, México, 1984.

-Espinosa, Pedro, Comunicaciones cambiadas entre el Excmo. Sr. ministro de Justicia y Negocios Eclesiásticos, y el Ilmo. Sr. obispo de Guadalajara, con motivo de la Ley de desamortización sancionada en 25 de junio de 1856, Tip. de Rodriguez, Guadalajara, 1957.
-Garza y Ballesteros, Lázaro de la, Contestaciones habidas entre el Ilmo. señor arzobispo y el Ministerio de Justicia con motivo de la ley sobre administración de ese ramo, Imp. de José Mariano Fernández. de Lara, México, 1855.

-Irigoyen, José Francisco, Protesta del Ilmo. y V. Sr. presidente y cabildo de la santa iglesia catedral de Puebla, contra el Manifiesto y Decretos publicados en Veracruz en julio del presente año, Imp. de Rivera, Puebla, 1859.

-Knowlton, Robert J., Los bienes del clero y la reforma mexicana, 1856-1910, FCE, México, 1985.

-Labastida y Dávalos, Pelagio Antonio de, Protesta del Ilmo. Sr. Dr. D. ..., obispo de Puebla, contra algunos de los artículos sancionados en la Constitución de la República Mexicana, publicada en su diócesis el 12 de abril de 1857, Imprenta de Juan N. Vega, Puebla, 1858.

Representación del Ilmo. Sr. obispo de Puebla pidiendo que se derogue el decreto sobre intervención de los bienes eclesiásticos de aquella diócesis y contestación del Excmo. Sr. ministro de Justicia, Imp. de Vicente G. Torres, México, 1856.

Carta pastoral que el Ilmo. Sr. Dr. don ... por la gracia de Dios y de la Santa Sede Apostólica obispo de la Puebla de los Ángeles dirige a todos sus diocesanos con motivo de la nueva Constitución publicada en la capital de su diócesis el día 12 del último abril, Imprenta de la Civilta Cattolica, Roma, 1857. 